Research Paper

\title{
Influence of Cervical Node Necrosis of Different Grades on the Prognosis of Nasopharyngeal Carcinoma Patients Treated with Intensity-Modulated Radiotherapy
}

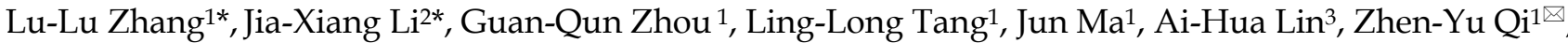 \\ Ying Sun ${ }^{1}$ \\ 1. Department of Radiation Oncology, Sun Yat-sen University Cancer Center, State Key Laboratory of Oncology in South China, Collaborative Innovation \\ Center for Cancer Medicine, 651 Dongfeng Road East, Guangzhou 510060, People's Republic of China; \\ 2. Department of Oncology, First People's Hospital of Zhaoqing City, Guangdong, People's Republic of China; \\ 3. Department of Medical Statistics and Epidemiology, School of Public Health, Sun Yat-sen University, Guangzhou, People's Republic of China. \\ * These authors contributed equally to this work.
}

$\triangle$ Corresponding authors: Ying Sun, PhD, Department of Radiation Oncology, Sun Yat-sen University Cancer Center, State Key Laboratory of Oncology in South China, Collaborative Innovation Center for Cancer Medicine, 651 Dongfeng Road East, Guangzhou 510060, People's Republic of China. Tel: +86-20-87343816; Fax: +86-20-87343295; Email: sunying@sysucc.org.cn Zhen-Yu Qi, PhD, Department of Radiation Oncology, Sun Yat-sen University Cancer Center, State Key Laboratory of Oncology in South China, Collaborative Innovation Center for Cancer Medicine, 651 Dongfeng Road East, Guangzhou 510060, People's Republic of China. Tel: +86-20-87343816; Fax: +86-20-87343295; Email: qizhy@sysucc.org.cn

(c) Ivyspring International Publisher. This is an open access article distributed under the terms of the Creative Commons Attribution (CC BY-NC) license (https://creativecommons.org/licenses/by-nc/4.0/). See http://ivyspring.com/terms for full terms and conditions.

Received: 2016.10.19; Accepted: 2016.12.23; Published: 2017.03.12

\begin{abstract}
Background: To analyze the prognostic value of cervical node necrosis (CNN) observed on pretreatment magnetic resonance imaging (MRI) in patients with nasopharyngeal carcinoma (NPC) treated with intensity-modulated radiotherapy (IMRT).

Patients and Methods: The medical records of 1423 NPC patients with cervical node metastasis who underwent IMRT were retrospectively reviewed. Lymph nodes in the axial plane of pretreatment MRI were classified as follows: grade $0 \mathrm{CNN}$, no hypodense zones; grade $1 \mathrm{CNN}, \leq 33 \%$ areas showing hypodense zones; and grade $2,>33 \%$ areas showing hypodense zones.

Results: CNN was detectable in 470/1423 (33\%) patients. Of these 470 patients, $213(15 \%)$ and 257 (18\%) exhibited grade 1 and grade 2 CNN. The grade 0 and grade 1 CNN groups showed significant differences with regard to distant metastasis-free survival (DMFS), but not overall survival (OS), regional relapse-free survival (RRFS), local relapse-free survival (LRFS), and disease-free survival (DFS). Significant differences were observed among the grade 0 and grade 2 CNN groups with regard to OS, RRFS, LRFS, DMFS, and DFS. Moreover, OS, LRFS, RRFS, and DFS were significantly different between the grade 1 and grade 2 CNN groups, whereas DMFS showed no significant differences. Univariate and multivariate analyses revealed CNN on MRI as a significant negative prognostic factor for OS, LRFS, RRFS, DMFS, and DFS in NPC patients.

Conclusions: NPC patients with CNN of different grades show various prognosis and failure patterns after IMRT. CNN on MRI can be adopted as a predictive factor for formulating individualized treatment plans for NPC patients.
\end{abstract}

Key words: Nasopharyngeal Carcinoma, Cervical Node necrosis, Intensity-Modulated Radiation Therapy, Prognosis.

\section{Introduction}

Nasopharyngeal carcinoma (NPC) is particularly endemic in China, where $>33,000$ new cases of NPC were diagnosed in 2012 [1, 2]. According to the anatomical characteristics of NPC and its high sensitivity to radiotherapy, radiotherapy was recommended as the primary treatment modality for these lesions $[3,4]$. Because of the rich lymphatic network in the nasopharynx, $60 \%-90 \%$ NPC patients present with cervical node metastasis on computed tomography (CT) or magnetic resonance imaging 
(MRI) [5-11].

Cervical node necrosis ( $\mathrm{CNN})$, which has an incidence of $22.5 \%-42.1 \%$ in NPC patients with NPC [11-14], is considered a reliable sign of a metastatic node $[15,16]$. Several previous studies have shown a correlation between the presence of hypodense lymph nodes, which indicate $\mathrm{CNN}$, or CNN on CT and the likelihood of regional failure after radiotherapy and/or chemotherapy in patients with head and neck cancer (HNC), but not NPC [17-19].

A recent study conducted by Lan et al. first demonstrated that $\mathrm{CNN}$ diagnosed on MRI was a negative prognostic factor for NPC patients; however, most of these patients were treated with two-dimensional conformal radiotherapy (2D-CRT) [20]. Of late, intensity-modulated radiation therapy (IMRT) has replaced 2D-CRT as the first choice of radiotherapy method [21, 22]. Because of the dosimetric advantages of IMRT, the evolution of radiotherapy techniques from 2D-CRT to IMRT has greatly improved disease control [23-25]. Unfortunately, no study has examined whether CNN remains a prognostic factor for NPC treated with IMRT.

Visible CNN on CT or MRI may serve as a marker of tumor hypoxia, which can result in a negative impact on the treatment effects, considering that hypoxic cells are less radiosensitive [26]. Therefore, different degrees of radiological necrosis may reflect different degrees of hypoxia, eventually affecting the prognosis of NPC. From the above perspectives, we conducted this retrospective study to assess the effects of $\mathrm{CNN}$ of different grades on the prognosis of NPC treated with IMRT.

\section{Materials and Methods}

\section{Patients}

This retrospective study was approved by the institutional ethics committee and the need for informed consent was waived. All the methods were carried out in accordance with the approved guidelines. We retrospectively reviewed the medical records of consecutive 1811 patients with previously untreated, biopsy-proven NPC with positive cervical node metastasis and no distant metastasis that was treated with IMRT between November 2009 and February 2012 at our Cancer Center. Among these 1811 patients, 308 without cervical node metastasis and 80 without pretreatment MRI scans of the neck and nasopharynx were excluded. Eventually, a total of 1423 NPC patients were enrolled in our study.

The routine staging work-up included a complete medical history and clinical examination; direct fiberoptic nasopharyngoscopy, hematology, and biochemistry profiles; MRI of the nasopharynx and whole neck; chest radiography; whole body bone scanning; and abdominal sonography. All patients were restaged according to the 7 th edition of the International Union against Cancer/American Joint Committee on Cancer (UICC/AJCC) system [27]. The clinical characteristics of the patients before treatment are listed in Table 1.

\section{Imaging protocol}

MRI was performed for all patients using a 1.5-T clinical MRI system (Signa CV/i; General Electric Healthcare, Chalfont St. Giles, United Kingdom) to examine the area from the suprasellar cistern to the inferior margin at the sternal end of the clavicle using a head and neck combined coil. Axial, coronal, and sagittal T1-weighted images (repetition time/echo time, 500-600 ms/10-20 ms) and axial T2-weighted images (4000-6000 ms/95-110 ms) were obtained before injection of contrast material. After intravenous injection of gadopentetate dimeglumine at a dose of $0.1 \mathrm{mmol} / \mathrm{kg}$ body weight, T1-weighted axial and sagittal sequences and T1-weighted fat-suppressed coronal sequences were sequentially acquired, with parameters similar to those used before contrast material injection. The section thicknesses were $5 \mathrm{~mm}$ for the axial plane, with intersection gaps of $1 \mathrm{~mm}$ and $6 \mathrm{~mm}$ for the coronal and sagittal planes, with intersection gaps of $1 \mathrm{~mm}$.

Table 1. Incidence of cervical node necrosis (CNN) at specific nodal levels in 1423 patients with nasopharyngeal carcinoma (NPC)

\begin{tabular}{|c|c|c|c|c|c|c|c|}
\hline \multirow[b]{2}{*}{ Grade of $\mathrm{CNN}^{*}$} & \multicolumn{7}{|c|}{ No. of patients (\%) with CNN at specific nodal levels\& } \\
\hline & $\begin{array}{l}\text { Retropharyngeal } \\
\text { lymph } \\
\text { Node }\end{array}$ & $\begin{array}{l}\text { Level I } \\
\text { lymph } \\
\text { nodes }\end{array}$ & $\begin{array}{l}\text { Level II } \\
\text { lymph } \\
\text { nodes }\end{array}$ & $\begin{array}{l}\text { Level III } \\
\text { lymph } \\
\text { nodes }\end{array}$ & $\begin{array}{l}\text { Level IV } \\
\text { lymph } \\
\text { Nodes }\end{array}$ & $\begin{array}{l}\text { Level V lymph } \\
\text { node }\end{array}$ & $\begin{array}{l}\text { Supraclavicular } \\
\text { lymph } \\
\text { nodes }\end{array}$ \\
\hline Grade $0 \mathrm{CNN}$ & $\begin{array}{l}1164 / 1423 \\
(81.80)\end{array}$ & $\begin{array}{l}1420 / 1423 \\
(99.79)\end{array}$ & $\begin{array}{l}1167 / 1423 \\
(82.01)\end{array}$ & $\begin{array}{l}1365 / 1423 \\
(95.92)\end{array}$ & $\begin{array}{l}1413 / 1423 \\
(99.30)\end{array}$ & $\begin{array}{l}1417 / 1423 \\
(99.58)\end{array}$ & $\begin{array}{l}1422 / 1423 \\
(99.93)\end{array}$ \\
\hline Grade $1 \mathrm{CNN}$ & $\begin{array}{l}127 / 1423 \\
(8.92)\end{array}$ & $\begin{array}{l}2 / 1423 \\
(0.14)\end{array}$ & $\begin{array}{l}86 / 1423 \\
(6.04)\end{array}$ & $\begin{array}{l}32 / 1423 \\
(2.25)\end{array}$ & $\begin{array}{l}4 / 1423 \\
(0.28)\end{array}$ & $\begin{array}{l}3 / 1423 \\
(0.21)\end{array}$ & $\begin{array}{l}1 / 1423 \\
(0.07)\end{array}$ \\
\hline Grade 2 CNN & $\begin{array}{l}132 / 1423 \\
(9.28)\end{array}$ & $\begin{array}{l}1 / 1423 \\
(0.07)\end{array}$ & $\begin{array}{l}170 / 1423 \\
(11.95)\end{array}$ & $\begin{array}{l}26 / 1423 \\
(1.83)\end{array}$ & $\begin{array}{l}6 / 1423 \\
(0.42)\end{array}$ & $\begin{array}{l}3 / 1423 \\
(0.21)\end{array}$ & $\begin{array}{l}0 / 1423 \\
(0.00)\end{array}$ \\
\hline
\end{tabular}

*The grading criteria for $\mathrm{CNN}$ were as follows: grade $0 \mathrm{CNN}$, no hypodense zones; grade $1 \mathrm{CNN}, \leq 33 \%$ nodal areas showing hypodense zones; and grade 2 , >33\% nodal areas showing hypodense zones.

\&Nodal levels were assigned according to the 2013 International Consensus Guidelines. 


\section{Diagnostic criteria for lymph node metastases}

Two radiologists specialized in HNC with more than 10 years of experience individually reviewed the MRI findings; any disagreements were resolved by consensus. Nodal levels were assigned according to the 2013 International Consensus Guidelines [28]. The diagnostic criteria for retropharyngeal and cervical lymph node metastases on MRI were as follows: lateral retropharyngeal nodes with a minimum axial diameter of $5 \mathrm{~mm}$ or more in the largest plane; any node in the median retropharyngeal group; cervical node with a minimum axial diameter of $11 \mathrm{~mm}$ or more at level II or another cervical node with a minimum axial diameter of $10 \mathrm{~mm}$ or more; lymph nodes of any size with central necrosis or a contrast-enhancing rim; nodal grouping characterized by three or more contiguous and confluent lymph nodes, each with a minimum axial diameter of 8 to 10 $\mathrm{mm}$; lymph nodes of any size with capsule invasion; the presence of indistinct nodal margins; irregular nodal capsular enhancement; and infiltration into the adjacent fat or muscle $[15,29]$.

\section{Grading criteria for CNN on MRI}

Two radiologists mentioned above reviewed the MRI scan images independently; any disagreements were resolved by consensus every 2 week. The diagnosis of necrosis on MRI was determined from a focal area of high-signal intensity on T2-weighted images or a focal area of low-signal intensity on contrast-enhanced T1-weighted images with or without a surrounding rim of enhancement [30].

The grading of $\mathrm{CNN}$ was evaluated in the largest axial T2-weighted MR plane for an individual necrotic lymph node by visual assessment. The grading criteria for CNN were as suggested by Munck et al: grade $0 \mathrm{CNN}$, no hypodense zones in axial T2-weighted MR images; grade $1 \mathrm{CNN}, \leq 33 \%$ nodal areas showing hypodense zones in axial T2-weighted MR images; and grade 2, >33\% nodal areas showing hypodense zones in axial T2-weighted MR images (Figure 1) [18].

\section{Treatment}

All patients underwent definitive radiotherapy using IMRT techniques. A detailed description of IMRT at our center has been previously reported [31]. According to the institutional guidelines in our center, radiotherapy alone was recommended for stage I disease, and concurrent chemoradiotherapy \pm neoadjuvant/adjuvant chemotherapy for stage II to IVB. Overall, among the 1423 patients, 113 (7.94\%) were treated with radiotherapy alone and 1310 $(92.06 \%)$ were treated with neoadjuvant, concomitant, or adjuvant chemotherapy.

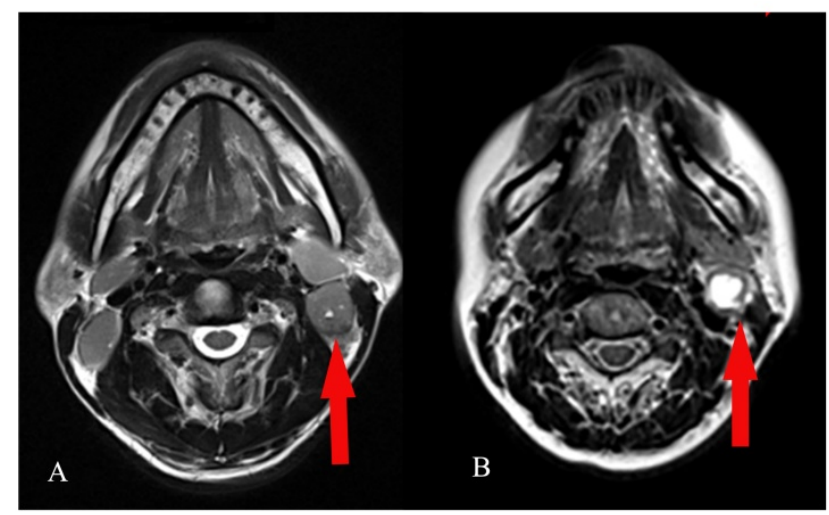

Figure 1. Visual assessment of the grading of cervical node necrosis (CNN) on magnetic resonance imaging (MRI). Examples of grade $1 \mathrm{CNN}: \leq 33 \%$ nodal areas showing hypodense zones in axial T2-weighted MR images (A) and grade 2 CNN: $>33 \%$ nodal areas showing hypodense zones in axial T2-weighted MR images (B).

\section{Follow-up}

The follow-up period was calculated from the day of therapy initiation to the date of the last examination or death. Patients were examined at least once every 3 months in the first 2 years, followed by once every 6 months during the subsequent 3 years or until death. Follow-up visits included a complete medical history, physical examination, hematology and biochemistry profiles, direct fiberoptic nasopharyngoscopy, MRI of the neck and nasopharynx, chest radiography, abdominal sonography, and a whole body bone scan.

We calculated overall survival (OS), regional relapse-free survival (RRFS), local relapse-free survival (LRFS), and distant metastasis-free survival (DMFS) from the first day of treatment to the date of death, local relapse, regional relapse, and distant metastasis, respectively. Disease-free survival (DFS) was calculated from the first day of treatment to the date of disease progression or death from any cause.

\section{Statistical analyses}

All statistical analyses were performed using Statistical Package for Social Sciences version 17.0 (SPSS, Chicago, IL, USA). A two-tailed $P$-value of $\leq 0.05$ was considered statistically significant. Pearson chi-square or Fisher's exact probability tests were used to compare categorical variables and treatment failure patterns among the three groups. If the expected count in any cell is less than 5, use the Fisher's exact probability tests, otherwise use the Chi-square test. OS, LRFS, RRFS, DMFS, and DFS rates were estimated using the Kaplan-Meier method, and differences among groups were assessed using log-rank tests. Univariate and multivariate Cox regression analyses were used to determine significant prognostic factors for NPC. Host factors 
(age and sex), tumor factors (T stage, $\mathrm{N}$ stage, WHO histological type, degree of $\mathrm{CNN}$ ), and treatment modes (presence or absence of chemotherapy) were included as covariates.

\section{Results}

\section{Treatment outcomes for the entire cohort}

The median follow-up period for the entire cohort was 48.59 months (range, 1.3-76 months). The overall 4-year OS, LRFS, RRFS, DMFS, and DFS were $89.50 \%, 94.30 \%, 95.10 \%, 88.50 \%$, and $80.60 \%$, respectively. By the last day of follow-up, 154 patients had succumbed, $135(9.49 \%)$ to cancer and 19 (1.34\%) to other causes $(P=0.339)$. In total, 258 patients experienced treatment failure; $163(11.45 \%), 79$ $(5.55 \%)$, and $67(4.71 \%)$ developed distant metastases, local recurrence, and regional recurrence, respectively.

\section{Incidence and grading of CNN}

Among the entire cohort of 1423 NPC patients with positive lymph node metastases, the rate of CNN was $470(33 \%)$. Of these, $213(15.0 \%)$ exhibited grade 1 CNN and $257(18 \%)$ exhibited grade 2 CNN. The incidence of CNN at specific nodal stations were summarized in Table 1 . The baseline characteristic of patients with grade 0 , grade 1 , and grade $2 \mathrm{CNN}$ are presented in Table 2.

\section{Subgroup analysis of treatment outcomes}

The 4-year OS rates in the grade 0 , grade 1 , and grade $2 \mathrm{CNN}$ groups were $91.70 \%, 89.00 \%$, and $81.50 \%$, respectively; the 4-year LRFS rates were $95.70 \%, 95.10 \%$, and $88.50 \%$, respectively; the 4 -year RRFS rates were $96.30 \%$, 95.20\%, and $90.60 \%$, respectively; the 4-year DMFS rates were $90.00 \%$, $85.40 \%$, and $82.30 \%$, respectively; and the 4 -year DFS rates were $84.00 \%, 78.00 \%$, and $69.80 \%$, respectively.

Kaplan-Meier survival curves for the three groups are shown in Figure 2. Differences in survival rates among the three groups are summarized in Table 3. There were significant differences among the three groups with regard to OS, LRFS, RRFS, DMFS, and DFS $(P<0.001$ for all). Significantly different values were observed for the grade 0 and grade 2 CNN groups $(P<0.001$ for OS, LRFS, RRFS, DMFS, and DFS). While DMFS $(P=0.034)$ was significantly different between the grade 0 and grade $1 \mathrm{CNN}$ groups, OS, LRFS, RRFS, and DFS $(P=0.527,0.679$, 0.447 , and 0.064 , respectively) were not. On the other hand, OS, LRFS, RRFS, and DFS were significantly different between the grade 1 and grade $2 \mathrm{CNN}$ groups $(P=0.013,0.024,0.043$, and 0.014, respectively), whereas DMFS was not $(P=0.133)$.

Table 2. Baseline characteristics of 1423 nasopharyngeal carcinoma (NPC) patients with grade $0-2$ cervical node necrosis (CNN)

\begin{tabular}{|c|c|c|c|c|c|}
\hline Characteristic & $\begin{array}{l}\text { No. of Patients (\%) with } \\
\text { Grade } 0 \text { CNN } \\
(\mathrm{n}=953)\end{array}$ & $\begin{array}{l}\text { No. of Patients (\%) with } \\
\text { Grade } 1 \text { CNN } \\
(\mathrm{n}=213)\end{array}$ & $\begin{array}{l}\text { No. of Patients (\%) with } \\
\text { Grade } 2 \text { CNN } \\
(\mathrm{n}=257)\end{array}$ & $\begin{array}{l}\text { Total patients } \\
(\mathrm{n}=1423)\end{array}$ & $P$-value \\
\hline Age, years & & & & & 0.867 \\
\hline$\leq 44$ & 473 (49.63) & $110(51.64)$ & 129 (50.19) & 712 & \\
\hline$>44$ & $480(50.37)$ & $103(48.36)$ & $128(49.81)$ & 711 & \\
\hline Sex & & & & & 0.198 \\
\hline Male & 714 (74.92) & 147 (69.01) & $192(74.71)$ & 1053 & \\
\hline Female & $239(25.08)$ & 66 (30.99) & 65 (25.29) & 370 & \\
\hline T stage* & & & & & 0.055 \\
\hline $\mathrm{T} 1$ & $158(16.58)$ & $29(13.62)$ & $30(11.67)$ & 217 & \\
\hline $\mathrm{T} 2$ & 131 (13.75) & $24(11.27)$ & 47 (18.29) & 202 & \\
\hline $\mathrm{T} 3$ & 487 (51.10) & 106 (49.77) & $127(49.42)$ & 720 & \\
\hline $\mathrm{T} 4$ & 177 (18.57) & $54(25.35)$ & $53(20.62)$ & 284 & \\
\hline$N$ stage* $^{*}$ & & & & & $<0.001$ \\
\hline $\mathrm{N} 1$ & $722(75.76)$ & 139 (65.26) & $145(56.42)$ & 1006 & \\
\hline $\mathrm{N} 2$ & $153(16.05)$ & $49(23.00)$ & $64(24.90)$ & 266 & \\
\hline N3a-3b & $78(8.18)$ & $25(11.74)$ & 48 (18.68) & 151 & \\
\hline Clinical stage* & & & & & 0.002 \\
\hline II & 217 (22.77) & 35 (16.43) & 45 (17.51) & 297 & \\
\hline III & $494(51.84)$ & $101(47.42)$ & $123(47.86)$ & 718 & \\
\hline IVA-B & $242(25.39)$ & $77(36.15)$ & $89(34.63)$ & 408 & \\
\hline WHO pathology & & & & & 0.717 \\
\hline Type I & $5(0.52)$ & $1(0.47)$ & $2(0.78)$ & 8 & \\
\hline Type II & $45(4.72)$ & $12(5.63)$ & $8(3.11)$ & 65 & \\
\hline Type III & 903 (94.75) & $200(93.90)$ & 247 (96.11) & 1350 & \\
\hline Chemotherapy & & & & & 0.006 \\
\hline No & 91 (9.55) & $10(4.69)$ & $12(4.67)$ & 113 & \\
\hline Yes & $862(90.45)$ & $203(95.31)$ & $245(95.33)$ & 1310 & \\
\hline
\end{tabular}

*According to the $7^{\text {th }}$ edition of the International Union against Cancer/American Joint Committee on Cancer staging system 

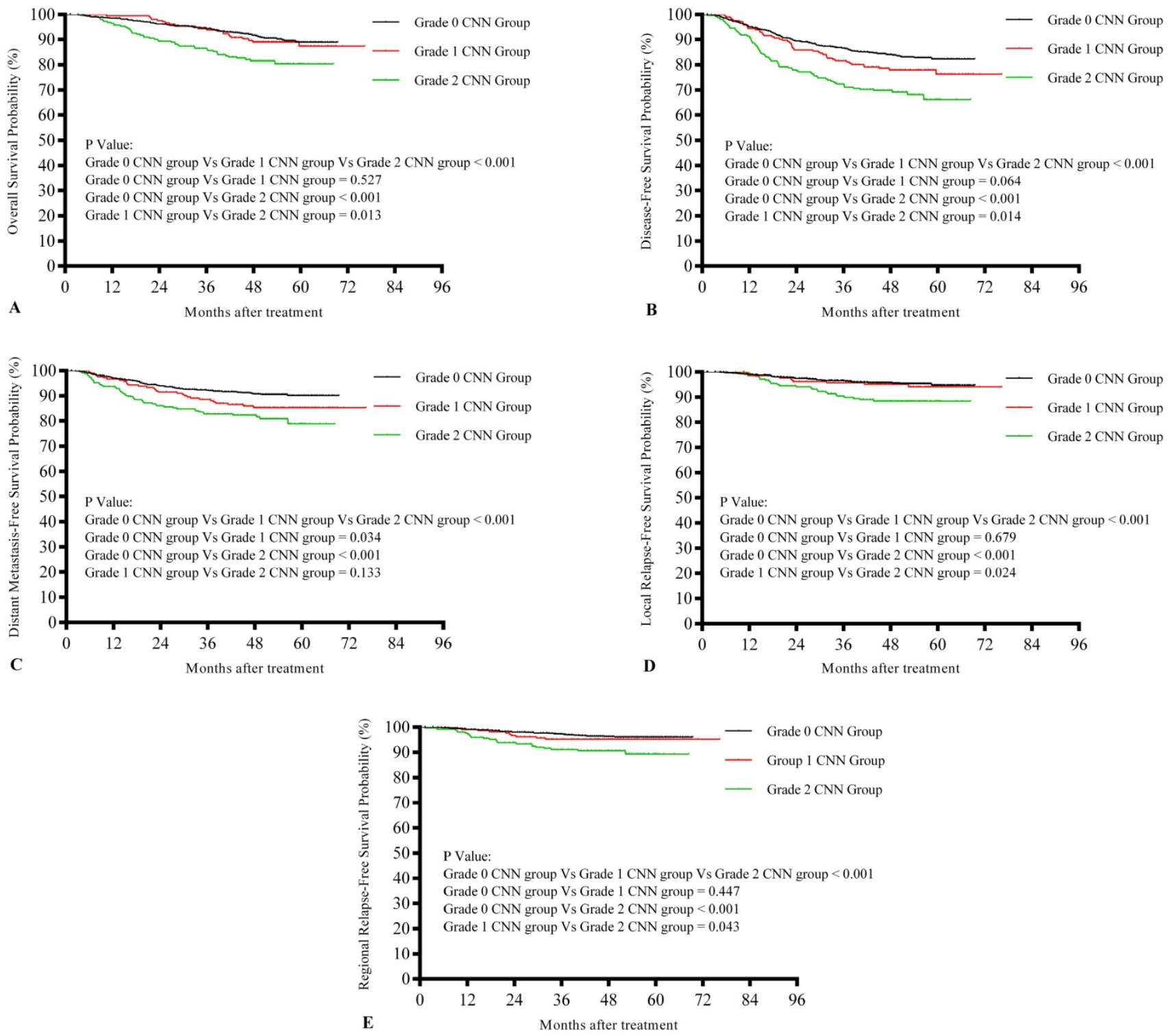

Figure 2. Kaplan-Meier survival curves showing overall survival rates (A), disease-free survival rates (B), distant metastasis-free survival rates (C), local relapse-free survival rates $(D)$, and regional relapse-free survival rates $(E)$ in nasopharyngeal carcinoma (NPC) patients with different grades of cervical node necrosis (CNN)

Table 3. Survival rates for 1423 nasopharyngeal carcinoma (NPC) patients with grade $0-2$ cervical node necrosis (CNN)

\begin{tabular}{|c|c|c|c|c|}
\hline \multirow[t]{6}{*}{ Endpoint } & \multicolumn{4}{|c|}{$P$-value } \\
\hline & Grade $0 \mathrm{CNN}$ group & Grade $0 \mathrm{CNN}$ group & Grade $0 \mathrm{CNN}$ group & Grade $1 \mathrm{CNN}$ group \\
\hline & & & & \\
\hline & Grade $1 \mathrm{CNN}$ group & Grade $1 \mathrm{CNN}$ group & Grade $2 \mathrm{CNN}$ group & Grade $2 \mathrm{CNN}$ group \\
\hline & & & & \\
\hline & Grade 2 CNN group & & & \\
\hline OS & $<0.001$ & 0.527 & $<0.001$ & 0.013 \\
\hline LRFS & $<0.001$ & 0.679 & $<0.001$ & 0.024 \\
\hline RRFS & $<0.001$ & 0.447 & $<0.001$ & 0.043 \\
\hline DMFS & $<0.001$ & 0.034 & $<0.001$ & 0.133 \\
\hline DFS & $<0.001$ & 0.064 & $<0.001$ & 0.014 \\
\hline
\end{tabular}

Abbreviations: DFS, disease-free survival; LRFS, local relapse-free survival; RRFS, regional relapse-free survival; DMFS, distant metastasis-free survival; OS, overall survival 
Table 4. Failure patterns in nasopharyngeal carcinoma (NPC) patients with grade $0-2$ cervical node necrosis (CNN)

\begin{tabular}{|c|c|c|c|c|c|}
\hline Failure patterns & Grade $0 \mathrm{CNN}$ group (\%) & Grade 1 CNN group (\%) & Grade 2 CNN group (\%) & Total & $P$-value \\
\hline Total & 141 & 44 & 73 & 258 & $<0.001$ \\
\hline Local only & 28 & 7 & 13 & 48 & 0.247 \\
\hline Regional only & 20 & 4 & 10 & 34 & 0.258 \\
\hline Distant only & 74 & 27 & 31 & 132 & 0.019 \\
\hline Local + regional & 7 & 3 & 3 & 13 & 0.599 \\
\hline Local + distant & 5 & 0 & 6 & 11 & 0.012 \\
\hline Regional + distant & 5 & 2 & 6 & 13 & 0.053 \\
\hline Local + regional + distant & 2 & 1 & 4 & 7 & 0.056 \\
\hline Total local & 42 & 11, & 26 & 79 & 0.002 \\
\hline Total regional & 34 & 10 & 23 & 67 & 0.001 \\
\hline Total distant & 86 & 30 & 47 & 163 & $<0.001$ \\
\hline \multicolumn{6}{|l|}{ Cause of death } \\
\hline Cancer & 76 & 18 & 41 & 135 & 0.339 \\
\hline No cancer & 10 & 5 & 4 & 19 & \\
\hline Total & 86 & 23 & 45 & 154 & \\
\hline
\end{tabular}

* P values were calculated using the chi-square test or Fisher exact test if indicated.

Table 5. Results of univariate and multivariate analyses of the prognostic factors for 1423 patients with nasopharyngeal carcinoma (NPC)

\begin{tabular}{|c|c|c|c|c|}
\hline \multirow{2}{*}{ Endpoint } & \multirow{2}{*}{ Variable } & \multirow{2}{*}{$\begin{array}{l}\begin{array}{l}\text { Univariate } \\
\text { analysis }\end{array} \\
P \text {-value }\end{array}$} & \multicolumn{2}{|l|}{ Multivariate analysis } \\
\hline & & & $\mathrm{HR}(95 \% \mathrm{CI})$ & $P$-value \\
\hline \multirow[t]{5}{*}{ OS } & Age & $<0.001$ & $1.759(1.263-2.499)$ & 0.001 \\
\hline & T stage & $<0.001$ & $1.667(1.368-2.031)$ & $<0.001$ \\
\hline & $\mathrm{N}$ stage & $<0.001$ & $1.545(1.349-1.770)$ & $<0.001$ \\
\hline & CNN & $<0.001$ & 1.362 (1.131-2.449) & 0.001 \\
\hline & $\begin{array}{l}\text { WHO } \\
\text { histological } \\
\text { type }\end{array}$ & $<0.001$ & $0.570(0.381-0.854)$ & 0.006 \\
\hline \multirow[t]{3}{*}{ LRFS } & T stage & 0.001 & $1.523(1.164-1.993)$ & 0.002 \\
\hline & $\begin{array}{l}\text { WHO } \\
\text { histological } \\
\text { type }\end{array}$ & $<0.001$ & $0.341(0.210-0.552)$ & $<0.001$ \\
\hline & $\mathrm{CNN}$ & $<0.001$ & $1.604(1.243-2.069)$ & $<0.001$ \\
\hline RRFS & $\mathrm{CNN}$ & $<0.001$ & $1.654(1.264-2.166)$ & $<0.001$ \\
\hline \multirow[t]{3}{*}{ DMFS } & $\mathrm{N}$ stage & $<0.001$ & 1.561 (1.370-1.779) & 0.017 \\
\hline & $\mathrm{CNN}$ & $<0.001$ & 1.361 (1.138-1.627) & $<0.001$ \\
\hline & T Stage & 0.003 & 1.315 (1.102-1.569) & 0.003 \\
\hline \multirow[t]{5}{*}{ DFS } & T stage & $<0.001$ & 1.268 (1.109-1.449) & 0.001 \\
\hline & $\mathrm{N}$ stage & $<0.001$ & $1.327(1.190-1.480)$ & $<0.001$ \\
\hline & $\mathrm{CNN}$ & $<0.001$ & $1.383(1.205-1.588)$ & $<0.001$ \\
\hline & Age & 0.004 & 1.363 (1.076-1.728) & 0.010 \\
\hline & $\begin{array}{l}\text { WHO } \\
\text { histological } \\
\text { type }\end{array}$ & 0.005 & $0.667(0.464-0.960)$ & 0.029 \\
\hline
\end{tabular}

Abbreviations: CNN, cervical node necrosis, DFS, disease-free survival; LRFS, local relapse-free survival; RRFS, regional relapse-free survival; DMFS, distant metastasis-free survival; OS, overall survival

\section{Subgroup analysis of patterns of treatment failure}

The patterns of treatment failure in the grade 0 , grade 1 , and grade $2 \mathrm{CNN}$ groups are presented in Table 4 . By the end of follow-up, $42(2.95 \%)$ patients in the grade $0 \mathrm{CNN}$ group, $11(0.77 \%)$ in the grade 1 CNN group, and $26(1.83 \%)$ in the grade $2 \mathrm{CNN}$ group experienced local failure $(P=0.002) ; 34(2.39 \%), 10$ $(0.70 \%)$, and $23(1.62 \%)$, respectively, developed regional failure $(P=0.001)$; and $86(6.04 \%), 30(2.11 \%)$, and $47(3.30 \%)$, respectively, developed distant metastases $(P<0.001)$.

\section{Univariate and multivariate analyses of prognostic factors for NPC}

In univariate analysis, CNN was identified as a significant prognostic factor for OS $(P<0.001)$, LRFS $(P<0.001)$, RRFS $(P<0.001)$, DMFS $(P<0.001)$, and DFS $(P<0.001$; Table 5$)$ in NPC patients. Consistent with the results of univariate analysis, $\mathrm{CNN}$ was identified as an independent prognostic factor for OS $(P=0.001)$, LRFS $(P<0.001)$, RRFS $(P<0.001)$, DMFS $(P<0.001)$, and DFS $(P<0.001)$.

Multivariate analysis also revealed age, $\mathrm{T}$ stage, $\mathrm{N}$ stage, and the WHO histological type as independent prognostic factors for OS $(P=0.001, P<$ $0.001, P<0.001, P<0.001$, and $P=0.006$, respectively); $\mathrm{T}$ stage and the WHO histological type as independent prognostic factors for LRFS $(P=0.002$ and $P<0.001) ; \mathrm{T}$ stage and $\mathrm{N}$ stage as independent prognostic factors for DMFS $(P=0.003$ and $P=0.017)$; and T stage, $\mathrm{N}$ stage, age, and $\mathrm{WHO}$ histological type as independent prognostic factors for DFS $(P=0.001$, $P<0.001, P=0.010$, and $P=0.029$ respectively; Table 5).

\section{Discussion}

The most important finding in the present large-scale retrospectively study was that CNN was an independent prognostic factor for poor clinical outcomes after IMRT in NPC patients. Patients with different degrees of CNN showed obvious prognosis and failure patterns. Compared with grade $0 \mathrm{CNN}$, grade $1 \mathrm{CNN}$ increased the risk of metastasis and grade $2 \mathrm{CNN}$ increased the risk of death, local relapse, regional relapse, and/or distant metastasis after IMRT. To the best of our knowledge, this is the first study on the prognostic effects of CNN of different grades on the treatment outcomes of NPC patients treated with IMRT. 
There are a few previous studies about the prognostic value of lymph node necrosis diagnosed on CT or MRI or poor nodal perfusion on $\mathrm{CT}$, which reflects the presence of necrosis, in HNC. Munck et al first established an association between nodal hypodensity on CT and a decreased OS rate in patients with advanced HNC treated with induction chemotherapy, 2D-CRT, and surgery in 1991 [18]. Then, Grabenbauer et al reported, in 1998, that nodal hypodensity on CT was an independent risk factor for a decreased OS rate and local and/or regional relapse in patients with stage III/IV HNC treated with 2D-CRT with or without chemotherapy [19]. In addition, Tang et al revealed, in 2014, that necrosis of metastatic retropharyngeal lymph nodes was a significant independent prognostic factor for DMFS and locoregional relapse-free survival in NPC patients treated with IMRT [29]. Lin et al recently reported that radiological lymph node necrosis on CT was an independent risk factor for OS, DFS, and nodal relapse-free survival in patients with HNC treated with IMRT with or without chemotherapy [17], while Lan et al concluded that CNN on MRI was a significant, independent, negative prognostic factor for OS, RRFS, DMFS, and DFS in NPC patients treated with 2D radiotherapy, three-dimensional (3D) radiotherapy, or IMRT [20]. However, the patients in most of these studies were treated with $2 \mathrm{D}$ or $3 \mathrm{D}$ radiotherapy. In recent years, IMRT has come to be accepted as a more advanced radiation technique for NPC, after retrospective and prospective studies have confirmed its efficacy for disease control [23-25]. However, it remains unclear whether the prognostic factors applicable to $2 \mathrm{D}$ or $3 \mathrm{D}$ radiotherapy can also be applied to IMRT.

In the present study, $\mathrm{CNN}$ was identified as an independent, negative prognostic factor for OS, LRFS, RRFS, DMFS, and DFS in NPC patients treated with IMRT. However, the precise mechanism underlying these negative prognostic effects remain unclear, although the following may explain our conclusion. Central necrosis in malignant lymph nodes is believed to occur after massive tumor infiltration [31] and is a late biological event in the evolution of tumor metastases in lymph nodes [32]. In addition, previous research demonstrated the presence of hypoxic cells around or in the area of necrosis [26, 33]; therefore, tumor necrosis may serve as a marker for intratumoral hypoxia. The presence of hypoxia in tumors may induce tumor cells to exhibit relatively poor sensitivity to radiotherapy or chemotherapy; moreover, it can lead to the expression of a hypoxia gene that can increase the tumor aggressiveness and accelerate progression $[34,35]$. This pathogenesis may explain why necrosis on MRI was found to be a significant negative prognostic factor for all endpoints (OS, LRFS, RRFS, DMFS, and DFS) in NPC patients.

Our study also demonstrated that grade $1 \mathrm{CNN}$ increased the risk of only metastasis, while grade 2 $\mathrm{CNN}$ increased the risk of both distant metastasis and death, local relapse, and/or regional relapse after IMRT. This was probably because different degrees of CNN represent varying severities of lymph node hypoxia. More severe lymph node hypoxia may result in poorer sensitivity to radiotherapy and chemotherapy. This may also explain for the significant differences in survival rates among the three CNN groups. We propose that clinicians should gain more insight into $\mathrm{CNN}$ on pretreatment MRI in NPC patients treated with IMRT. We predict that further improvement in the survival of NPC patients with CNN, particularly grade $2 \mathrm{CNN}$, may be achieved by more intensive treatment, although further evidence is needed to prove this hypothesis. The limitation of our study was the unavoidable biases inherent in retrospective studies; however, our results were consistent with those of a previous study conducted by Lan et al [20].

\section{Conclusions}

In conclusion, the results of our study suggest that $\mathrm{CNN}$ is an independent prognostic factor for OS, LRFS, RRFS, DMFS, and DFS in NPC patients treated with IMRT. Patients with different degrees of CNN may show various prognosis and failure patterns. Compared with grade $0 \mathrm{CNN}$, grade $1 \mathrm{CNN}$ can increase the risk of metastasis and grade $2 \mathrm{CNN}$ can increase the risk of death, local relapse, regional relapse, and/or distant metastasis after IMRT. CNN on MRI can thus be adopted as a predictive factor to aid in individualized treatment planning for NPC patients.

\section{Abbreviations}

$\mathrm{CNN}$ : cervical node necrosis; MRI: magnetic resonance imaging; NPC: nasopharyngeal carcinoma; IMRT: intensity-modulated radiotherapy; DMFS: distant metastasis-free survival; OS: overall survival; RRFS: regional relapse-free survival; LRFS: local relapse-free survival; DFS: disease-free survival; CT: computed tomography; HNC: head and neck cancer; 2D-CRT: two-dimensional conformal radiotherapy; UICC/AJCC: International Union against Cancer/American Joint Committee on Cancer

\section{Acknowledgements}

This work was supported by grants from the National Natural Science Foundation of China (No. 8172409), the Sun Yat-Sen University Clinical Research 5010 Program (No. 2012011). The funders 
had no role in study design, data collection and analysis, decision to publish, or preparation of the manuscript.

\section{Competing Interests}

The authors have declared that no competing interest exists.

\section{References}

1. [Internet] IARC. GLOBOCAN 2012: Estimated Cancer Incidence, Mortality and Prevalence Worldwide in 2012. http://globocan.iarc.fr/Pages/ fact sheets_population.aspx [Accessed: July 27, 2015.

2. Kuang-Rong Wei, Rong-Shou Zheng, Si-Wei Zhang, et al. Nasopharyngeal carcinoma incidence and mortality in China in 2010. Chin J Cancer 2014; 33(8):381-7

3. Chan AT. Nasopharyngeal carcinoma. Annals of oncology: official journal of the European Society for Medical Oncology / ESMO 2010; 21 Suppl 7:vii308-12.

4. Lee AW, Lin JC, Ng WT. Current management of nasopharyngeal cancer. Seminars in radiation oncology 2012; 22(3):233-44.

5. Sham JS, Cheung YK, Choy D, et al. Computed tomographyevaluation of neck node metastases from nasopharyngeal carcinoma. Int J Radiat Oncol Biol Phys 1993; 26: 787-92

6. Chong VF, Fan YF, Khoo JB. Retropharyngeal lymphadenopathy in nasopharyngeal carcinoma. Eur I Radiol 1995; 21:100-5.

7. Ng SH, Chang TC, Ko SF, et al. Nasopharyngeal carcinoma: MRI and CT assessment. Neuroradiology 1997; 39:741-6.

8. King AD, Ahuja AT, Leung SF, et al. Neck node metastases from nasopharyngeal carcinoma: MRI of patterns of disease. Head Neck 2000; 22:275-81.

9. Kao CH, Hsieh JF, Tsai SC, et al. Comparison of 18F-2-fluoro- 2- deoxyglucose positron emission tomography and computed tomography in detection of cervical lymph node metastases of nasopharyngeal carcinoma. Ann Otol Rhinol Laryngol 2000; 109:1130-4

10. Wang XS, Hu CS, Wu YR, et al. Analysis of computed tomography-based distribution of metastatic cervical nodes in 218 cases of nasopharyngeal carcinoma. Ai Zheng 2004; 23:1056-9.

11. Liu LZ, Zhang GY, Xie CM, et al. Magnetic resonance imaging of retropharyngeal lymph node metastasis in nasopharyngeal carcinoma: Patterns of spread. Int J Radiat Oncol Biol Phys 2006; 66:721-30.

12. Mao YP, Liang SB, Liu LZ, et al. The $\mathrm{N}$ staging system in nasopharyngeal carcinoma with radiation therapy oncology group guidelines for lymph node levels based on magnetic resonance imaging. Clin Cancer Res 2008; 14(22):7497-503

13. Ding ZX, Liang BL, Shen J, et al. Value of Radiation Therapy Oncology Group guidelines based on MR imaging in diagnosing lymph node metastasis of nasopharyngeal carcinoma [in Chinese]. Ai Zheng 2009; 28(5):533-7.

14. Wang XS, Hu CS, Ying HM, et al. Patterns of retropharyngeal node metastasis in nasopharyngeal carcinoma. Int I Radiat Oncol Biol Phys 2009; 73(1): 194-201.

15. van den Brekel MW, Stel HV, Castelijns JA, et al. Cervical lymph node metastasis: assessment of radiologic criteria. Radiology 1990; 177:379-84.

16. Som PM. Update on imaging metastatic cervical lymph nodes: criteria and differential diagnosis. AJR Am I Roentgenol 1992; 158:961-9.

17. Lin YC, Chen SW, Hsieh TC, et al. Risk stratification of metastatic neck nodes by CT and FET in Patients with Head and Neck Cancer Receiving Definitive Radiotherapy. J Nucl Med 2015;56(2):183-9.

18. Munck JN, Cvitkovic E, Piekarski JD, et al. Computed tomography of metastatic lymph nodes as a treatment-related prognostic factor in advanced head-and-neck cancer. J Nat Cancer Inst 1991; 83:569 -75.

19. Grabenbauer GG, Steininger $\mathrm{H}$, Meyer M, et al. Nodal CT density and total tumor volume as prognostic factors after radiation therapy of stage III/IV head-and-neck cancer. Radiother Oncol 1998; 47:175-83.

20. Lan M, Huang $\mathrm{Y}$, Chen $\mathrm{CY}$, et al. Proonostic value of cervical nodal necrosis in nasopharyngeal carcinoma: analysis if 1800 patients with positive cervical nodal metastasis at MR imaging. Radiology 2015; 276(2):536-44

21. Saarilahti K, Kouri M, Collan J, et al. Intensity modulated radiotherapy for head and neck cancer: evidence for preserved salivary gland function. Radiother Oncol 2005; 74:251-8

22. Teo PM, Ma BB , Chan AT. Radiotherapy for nasopharyngeal carcinoma transition from two-dimensional to three-dimensional methods. Radiother Oncol 2004; 73:163-72.

23. Tham IW, Hee SW, Yeo RM, et al. Treatment of nasopharyngeal carcinoma using intensity-modulated radiotherapy-the national cancer centre singapore experience. Int J Radiat Oncol Biol Phys 2009; 75(5):1481-6.

24. Lee N, Xia P, Quivey JM, et al. Intensity-modulated radiotherapy in the treatment of nasopharyngeal carcinoma: an update of the UCSF experience. Int J Radiat Oncol Biol Phys 2002; 53(1): 12-22.

25. Kam MK, Teo PM, Chau RM, et al. Treatment of nasopharyngeal carcinoma with intensity-modulated radiotherapy: the Hong Kong experience. Int $J$ Radiat Oncol Biol Phys 2004; 60(5): 1440-50.
26. Ljungkvist AS, Bussink J, Rijken PF, et al. Vascular architecture, hypoxia, and proliferation in first-generation xenografts of human head-and-neck squamous cell carcinomas. Int J Radiat Oncol Biol Phys 2002; 54(1): 215-28

27. Edge SB, Compton CC. The American Joint Committee on Cancer: the 7th edition of the AJCC cancer staging manual and the future of TNM. Annals of surgical oncology 2010; 17(6):1471-4.

28. Grégoire V, Ang K, Budach W, et al. Delineation of the neck node levels for head and neck tumors: a 2013 update. DAHANCA, EORTC, HKNPCSG, NCIC CTG, NCRI, RTOG, TROG consensus guidelines. Radiother Oncol 2014; 110:172-81.

29. Tang L, Li L, Mao Y, et al. Retropharyngeal lymph node metastasis in nasopharyngeal carcinoma detected by magnetic resonance imaging: prognostic value and staging categories. Cancer 2008; 113(2):347-54.

30. King AD, Tse GM, Ahuja AT, et al. Necrosis in metastatic neck nodes: diagnostic accuracy of CT, MR imaging, and US. Radiology 2004; 230(3):720-6.

31. Don DM, Anzai Y, Lufkin RB, et al. Evaluation of cervical lymph node metastases in squamous cell carcinoma of the head and neck. Laryngoscope 1995; 105(7 Pt 1):669-74.

32. Som P. Lymph nodes of the neck. Radiology. 1987; 165(3):593-600.

33. Sham JS, Cheung YK, Choy D, Chan FL, Leong L. Computed tomography evaluation of neck node metastasis from nasopharyngeal carcinoma. Int I Radiat Oncol Biol Phys 1993; 26(5):787-92.

34. Toustrup K, Sørensen BS, Lassen P, et al. Gene expression classifier predicts for hypoxic modification of radiotherapy with nimorazole in squamous cell carcinomas of the head and neck. Radiother Oncol 2012; 102(1):122-9.

35. Toustrup K, Sørensen BS, Nordsmark M, et al. Development of a hypoxia gene expression classifier with predictive impact for hypoxic modification of radiotherapy in head and neck cancer. Cancer Res 2011; 71(17):5923-31. 